\title{
Interactive comment on "Improved
}

1-km-resolution $\mathrm{PM}_{2.5}$ estimates across China using the space-time extremely randomized trees" by Jing Wei et al.

Jing Wei et al.

weijing_rs@163.com

Received and published: 25 January 2020

The comment was uploaded in the form of a supplement: https://www.atmos-chem-phys-discuss.net/acp-2019-815/acp-2019-815-AC3supplement.pdf 2019. 